\title{
Structural and Charge Density Properties of Iron Doped Nickel Oxide Synthesized by Co- precipitation Method
}

\author{
S. Sasikumar, S. Saravanakumar, D. Sivaganesh, S. Asath Bahadur
}

\begin{abstract}
Ni}_{1-x} \mathrm{Fe}_{x} \mathrm{O}(\mathrm{x}=0.00,0.01,0.02,0.03,0.04)$ samples were successfully synthesized by co-precipitation method. Room temperature structural properties were analyzed by PXRD studies and Rietveld profile refinement technique. The structural results revealed that the samples assigned by cubic symmetry with Fm$3 m$ space group. Effects of structural properties with respect to the Iron substitutions in $\mathrm{NiO}$ matrix was investigated. Charge density profiles of the prepared materials were also investigated by maximum entropy method. From MEM analysis, it found that the ionic nature of $\mathrm{Ni}-\mathrm{O}$ bond decreased. The surface morphologies were determined by scanning electron microscopic (SEM) measurements.
\end{abstract}

Keywords: Rietveld refinement, bonding nature, crystal structure, maximum entropy method.

\section{INTRODUCTION}

$\mathrm{I}_{1}$ n recent decades, the metal oxides have been focused more attracted applications. Nickel oxide materials have paid important attention because of their mechanical, electrical, catalytic and magnetic properties [1-5]. The preparation of metal oxide materials plays vital role in the conversion process of energy [6]. NiO materials are one of the most promising candidates and used in important applications in batteries, capacitors, smart windows, sensors for gas, drug delivery in medical application and magnetic bar codes [7-12]. Nickel oxide material can be synthesized by different methods such as hydrothermal, co-precipitation, electrospinning, reflux methods, etc. [13-16]. The NiO material is a p-type semiconductor with wide energy band gap and it possess magnetic properties such as ferromagnetic, antiferromagnetic, super-paramagnetic behaviour and the magnetic order depending on the size of the particle and synthesis method. Sohaib et al., reported that the $\mathrm{NiO}$ is an antiferromagnetic insulating material with a Neel temperature of $523 \mathrm{~K}$ [17].

Revised Manuscript Received on December 29, 2019.

* Correspondence Author

S. Sasikumar, Department of Physics, International Research centre, Kalasalingam Academy of Research and Education, Krishnankoil -626126, Tamil Nadu, India. Email: sasikuhan@gmail.com

S. Saravanakumar, Department of Physics, International Research centre, Kalasalingam Academy of Research and Education, Krishnankoil 626126, Tamil Nadu, India. Email: saravanaphysics@ gmail.com

D. Sivaganesh, Department of Physics, International Research centre, Kalasalingam Academy of Research and Education, Krishnankoil - 626126, Tamil Nadu, India. Email: ganesh.siva650@gmail.com

S. Asath Bahadur*, Department of Physics, International Research centre, Kalasalingam Academy of Research and Education, Krishnankoil 626126, Tamil Nadu, India. Email: s.asathbahadur@klu.ac.in
In this present attempt, $\mathrm{Ni}_{1-\mathrm{x}} \mathrm{Fe}_{\mathrm{x}} \mathrm{O}(\mathrm{x}=0.00,0.01,0.02$, $0.03,0.04)$ samples were successfully synthesized by coprecipitation method and the effects of Iron dopant on the structural, morphological and charge density properties. The present report details the effects on structural properties with various doping percentages. The influence of Iron doping on the structural property has been experimentally analyzed via powder X-ray diffraction and Rietveld profile refinements [18]. The primary aim of this work details with the distribution of charges inside the unit cell of the samples. In general, the electronic property of the materials plays a vital role in electrical properties, which helps to know about the bonding nature between constituent atoms. The charge density distribution maps and interatomic chemical bonding futures inside the unit cell of $\mathrm{Ni}_{1-\mathrm{x}} \mathrm{Fe}_{\mathrm{x}} \mathrm{O}(\mathrm{x}=0.00,0.01,0.02$, $0.03,0.04)$ samples were reconstructed by maximum entropy method (MEM) [19] by the structure factor evolved by Rietveld profile refinement [18].

\section{EXPERIMENTAL}

\section{A. Materials synthesis}

$\mathrm{Ni}_{1-\mathrm{x}} \mathrm{Fe}_{\mathrm{x}} \mathrm{O}(\mathrm{x}=0.00,0.01,0.02,0.03,0.04)$ samples were synthesized by co-precipitation method. To prepare the samples, Nickel nitrate was used as starting materials. $0.5 \mathrm{M}$ of Nickel nitrate solution was added with $1 \mathrm{M}$ of $\mathrm{NaOH}$ solution, which is used as a precipitation agent. The solution was stirred for $2 \mathrm{~h}$ and precipitation was washed to remove $\mathrm{Na}$ ions and finally dried at $80^{\circ} \mathrm{C}$. Further, the doped samples were prepared by the same procedure for all the Iron doped $\mathrm{NiO}$ with the addition of Iron nitrate. Finally, the $\mathrm{NiO}$ and $\mathrm{NiO}$ : $\mathrm{Fe}$ samples were calcined at $700^{\circ} \mathrm{C}$ for $2 \mathrm{~h}$

\section{B. Materials characterization}

The Powder XRD and Rietveld profile refinement method [18] analysis were performed to determine the phase identification of the prepared samples using JANA2006 software [20]. The room temperature PXRD data sets were collected by Burker X-ray diffractometer with $\mathrm{CuK} \alpha$ monochromatic radiation from $20^{\circ}-100^{\circ}$ for a step width of $0.02^{\circ}$. Microstructure and surface morphology were done by scanning electron microscopic images (SEM) (Zeiss EVO MA15 Research). 


\section{RESULTS AND DISCUSSION}

\section{A. XRD and Rietveld profile refinement analysis}

Fig. 1 shows the powder XRD profiles of $\mathrm{Ni}_{1-\mathrm{x}} \mathrm{Fe}_{\mathrm{x}} \mathrm{O}$ $(\mathrm{x}=0.00,0.01,0.02,0.03,0.04)$ samples. All the observed PXRD profiles for pure $\mathrm{NiO}$ and $\mathrm{NiO}: \mathrm{Fe}$ samples assigned by cubic structure with space group Fm-3m. The PXRD patterns are also well matched with standard JCPDS database (Card No. 04-0835) without any trace of addition extra phases. When increasing the dopant, the intensity of the diffraction peaks become reduce and broader due to the Fe ion as shown in fig. 1. The characteristic main peak of the samples shifted towards higher $2 \theta$ side for all samples (fig. 1 (b)). This attributed that the substitution of the impurity ions $\mathrm{Fe}$ distorts the host $\mathrm{NiO}$ matrix. The estimated cell parameters decreased with respect to the substitution of $\mathrm{Fe}$ ion in the $\mathrm{NiO}$ matrix. The lattice constant ' $\mathrm{a}$ ' for the cubic structure of $\mathrm{Ni}_{1-\mathrm{x}} \mathrm{Fe}_{\mathrm{x}} \mathrm{O}$ ( $\left.\mathrm{x}=0.00,0.01,0.02,0.03,0.04\right)$ samples calculated using the following equation [21],

$$
\frac{1}{d^{2}}=\left(\frac{h^{2}+k^{2}+l^{2}}{a^{2}}\right) \text {. }
$$

In order to find more information about crystal structure, the Rietveld refinement has been performed using JANA2006 [20] software by the PXRD data. The fitted profiles of samples with $\mathrm{x}=0.00,0.01,0.02,0.03,0.04$ compositions are shown in figs. 2 (a)-(e). The results of Rietveld profile refinement with acceptable R-factors such as $R_{p}, R_{o b s}$ and GOF extracted from profile refinement results and the values are given in Table I. From the Rietveld profile refinement [18], it is noticed that the cell parameters increase while increasing $\mathrm{Fe}$ substitution. The average crystallite size of samples estimated using DebyeScherer's formula [22].

$$
, D=\frac{0.9 \lambda}{\beta \cos \theta}
$$

where $\beta$ is FWHM (full width half maximum of the peak), $\lambda$ is wavelength and $\theta$ is Bragg angle. The calculated average crystallite size (D) values listed in Table I.
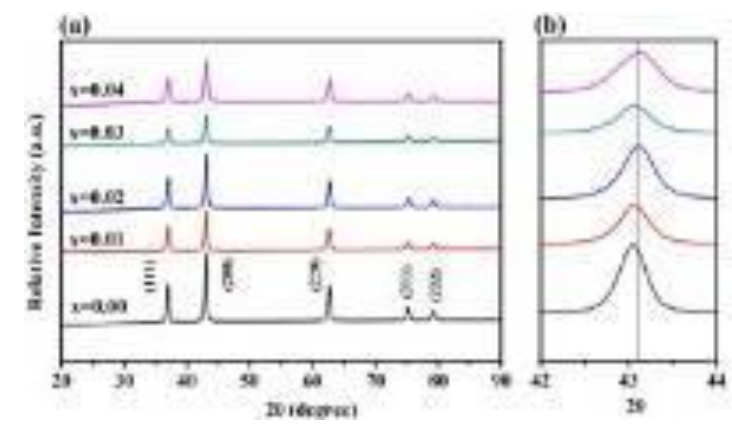

Fig. 1. (a) XRD patterns of $\mathrm{Ni}_{1-\mathrm{x}} \mathrm{Fe}_{\mathrm{x}} \mathrm{O}(\mathrm{x}=0.00,0.01$, 0.02, 0.03, 0.04) samples (b) Enlarged XRD patterns from $42^{\circ}-44^{\circ}$.
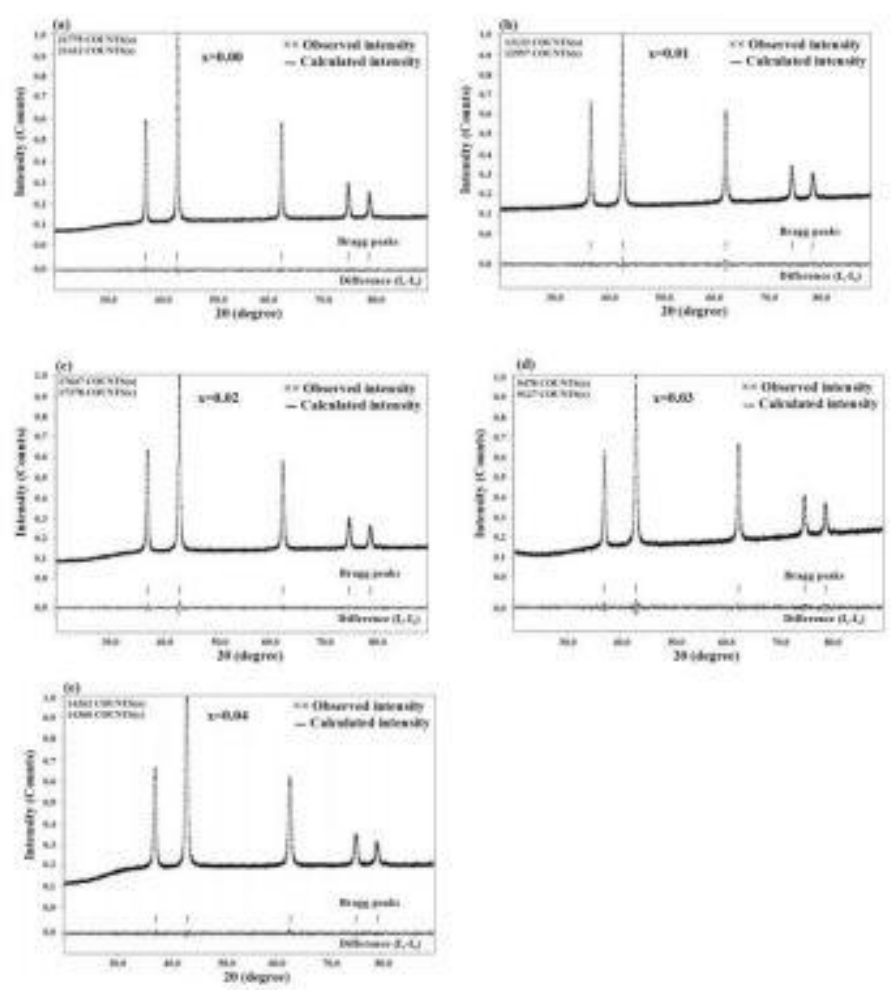

Fig. 2. Fitted $X$-ray profiles for $\mathrm{Ni}_{1-\mathrm{x}} \mathrm{Fe}_{\mathrm{x}} \mathrm{O}$ samples, (a) $\mathrm{x}$ $=0.00,(\mathrm{~b}) \mathrm{x}=0.01$, (c) $\mathrm{x}=0.02$, (c) $\mathrm{x}=0.03$, (c) $\mathrm{x}=$ 0.04

Table-I: Structural parameters of $\mathrm{Ni}_{1-\mathrm{x}} \mathrm{Fe}_{\mathrm{x}} \mathrm{O}(\mathrm{x}=\mathbf{0 . 0 0}$, $0.01,0.02,0.03,0.04)$ samples through refinement of powder XRD data

\begin{tabular}{|c|c|c|c|c|c|}
\hline Parameter & $\mathbf{x = 0 . 0 0}$ & $\mathbf{x = 0 . 0 1}$ & $\mathbf{x = 0 . 0 2}$ & $\mathbf{x = 0 . 0 3}$ & $\begin{array}{c}\mathbf{x =} \\
\mathbf{0 . 0 4}\end{array}$ \\
\hline $\mathrm{a}=\mathrm{b}=\mathrm{c}(\AA)$ & $4.178(6)$ & $4.179(2)$ & $4.185(9)$ & $4.172(2)$ & $\begin{array}{c}4.178(7 \\
)\end{array}$ \\
\hline $\begin{array}{c}\text { Volume } \\
\left(\AA^{3}\right)\end{array}$ & $72.97(1)$ & $73.02(1)$ & $73.28(1)$ & $72.65(2)$ & $\begin{array}{c}72.97(1 \\
)\end{array}$ \\
\hline $\begin{array}{c}\text { Density } \\
(\mathrm{gm} / \mathrm{cc})\end{array}$ & 6.79 & 6.78 & 6.76 & 6.81 & 6.78 \\
\hline $\mathrm{R}_{\mathrm{p}}(\%)$ & 1.55 & 1.85 & 1.88 & 2.08 & 1.46 \\
\hline $\mathrm{R}_{\text {obs }}(\%)$ & 0.17 & 0.13 & 1.81 & 0.26 & 0.33 \\
\hline $\mathrm{GOF}$ & 1.07 & 1.12 & 1.30 & 1.14 & 1.02 \\
\hline $\mathrm{F}(000)$ & 144 & 144 & 144 & 1.44 & 1.44 \\
\hline $\begin{array}{c}\text { Thermal } \\
\text { parameters } \\
\text { Ni/Fe }\end{array}$ & 1.15 & 1.19 & 1.48 & 1.26 & 1.43 \\
\hline O & 1.02 & 0.99 & 1.07 & 0.97 & 1.04 \\
\hline $\begin{array}{c}\text { Crystallite } \\
\text { size (nm) }\end{array}$ & 28 & 26 & 23 & 24 & 17 \\
\hline
\end{tabular}

\section{B. Electron density analysis}

The charge density distribution studies are very useful to understand the physical properties of the materials, like optical and electrical properties. In this work, the charge densities were calculated inside the unit cell using maximum entropy method [19]. Each unit cell of the sample was divided into $64 \times 64 \times 64$ pixels along the three axes and each pixel fixed as $\mathrm{F}_{000} / \mathrm{a}_{0}{ }^{3}$ using PRIMA [23] and VESTA [24] software. Figs. 3 (a)-(e) show the charge density analysis with shaded of iso-surfaces inside the unit cell. Fig. 4 (a) shows the 3D structure with (200) shaded plane. 
Figs. 4 (b)-(c) show the 2D maps on (200) plane with isosurface level of $0-1 \mathrm{e} / \AA^{3}$ with an contour interval of 0.04 $\mathrm{e} / \AA^{3}$. From the 2D planes, the contour lines show the accumulation of charges between the Ni-O bonds (Figs. 4 (b) - (f)). The contour lines come closer when the substitution of Iron content in the $\mathrm{NiO}$ matrix. This authenticates ionic nature of Ni-O bond is decreased. These results are consistent with PXRD data. Figs. 5 (a) and (b) show the 1D charge density profiles along Ni-O bond, which also elucidate length of the bond and mid-bond charge densities and are listed in Table II.
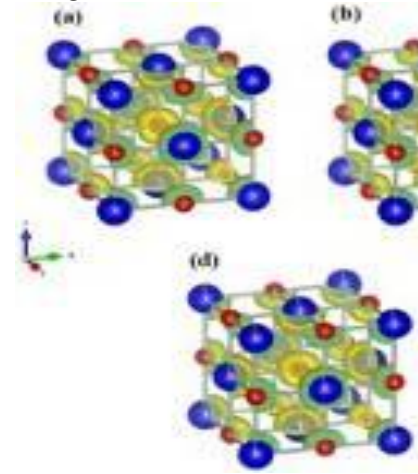
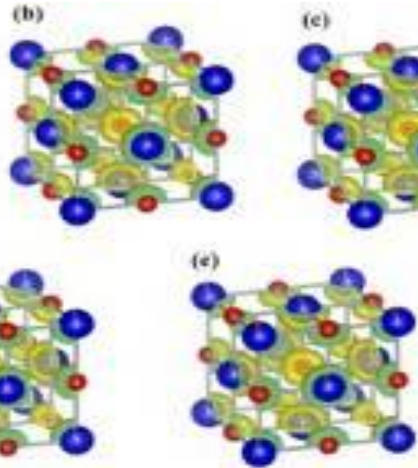

Fig. 3. 3D electron density of Ni1-xFexO samples, (a) $x$ $=0.00,(b) x=0.01,(c) x=0.02,(d) x=0.03,(e) x=$ 0.04.
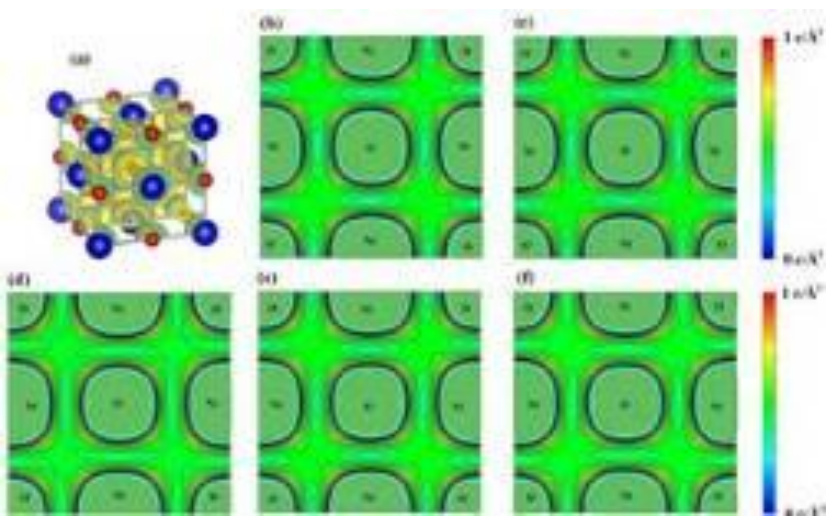

Fig. 4. 3D unit cell of Ni1-xFexO samples with (a) (200) plane shaded and 2D electron density distribution on (200) plane for Ni1-xFexO samples, (b) $x=0.00$, (c) $x=0.01$, (d) $x=0.02$ (e) $x=0.03$, (f) $x=0.04$.

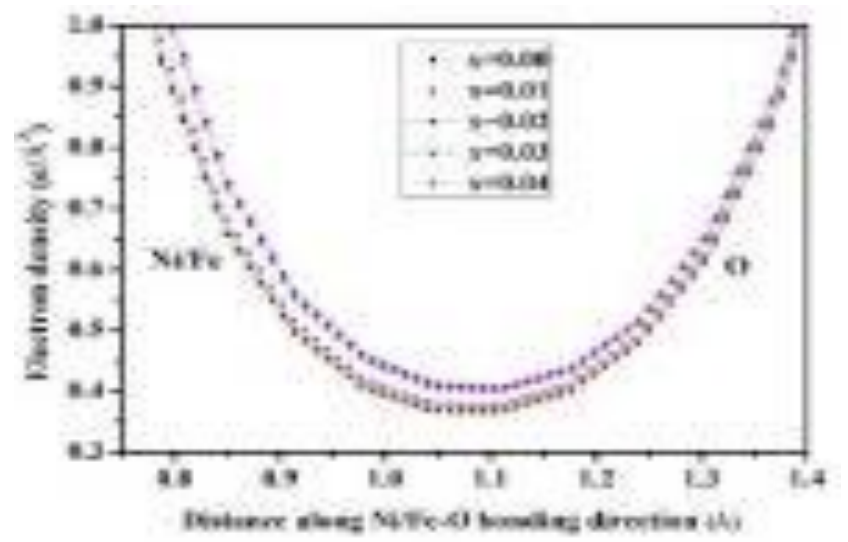

Fig. 5. 1D electron density profiles along the $\mathrm{Ni}-\mathrm{O}$ bonding directions for Ni1-xFexO samples.

Table-II: Charge density parameters of Ni-O bond for

\begin{tabular}{|c|c|c|}
\hline \multicolumn{3}{|c|}{$\mathrm{Ni}_{1-\mathrm{x}} \mathrm{Fe}_{\mathrm{x}} \mathrm{O}$ samples } \\
\hline \multirow{2}{*}{ Concentrations } & \multicolumn{2}{|c|}{$\mathrm{Ni} / \mathrm{Fe}-\mathrm{O}$} \\
\hline & Bond length $(\check{A})$ & $\begin{array}{c}\text { Mid bond electron } \\
\text { density }\left(e / \AA^{3}\right)\end{array}$ \\
\hline $\mathrm{x}=0.00$ & 2.0894 & 0.3666 \\
\hline $\mathrm{x}=0.01$ & 2.0898 & 0.3664 \\
\hline $\mathrm{x}=0.02$ & 2.0925 & 0.4062 \\
\hline $\mathrm{x}=0.03$ & 2.0863 & 0.3768 \\
\hline $\mathrm{x}=0.04$ & 2.0893 & 0.4016 \\
\hline
\end{tabular}

\section{Surface morphology and EDS analysis}

Figs. 6 (a)-(e) show the surface morphology images of $\mathrm{Ni}_{1-\mathrm{x}} \mathrm{Fe}_{\mathrm{x}} \mathrm{O}$ samples measured by scanning electron microscopy. The SEM images were recorded with magnification of around $\times 25000$. All samples show fractured surface morphology. Figs. 6 (a)-(e) confirm that the substitution of Iron content in the $\mathrm{NiO}$ matrix helps to enhance the morphology. With the substitution of the Iron content the particle size of the samples increased with respect to the dopant.

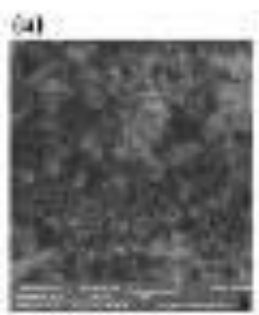

(d)

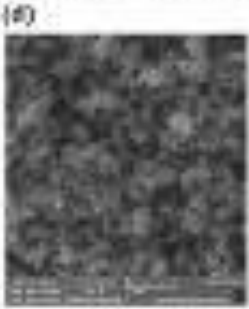

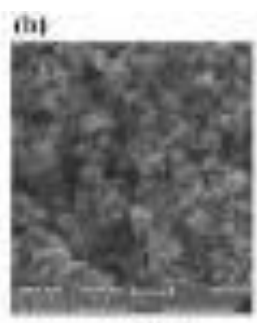

(r)

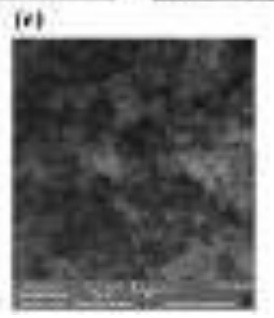

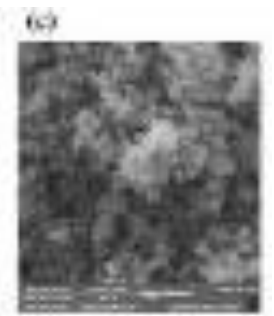

Fig. 6. SEM images of Ni1-xFexO samples (a) $x=0.00$, (b) $x=0.01$, (c) $x=0.02$, (d) $x=0.03$, (e) $x=0.04$.

\section{CONCLUSION}

In this work, $\mathrm{Ni}_{1-\mathrm{x}} \mathrm{Fe}_{\mathrm{x}} \mathrm{O}(\mathrm{x}=0.00,0.01,0.02,0.03,0.04)$ samples were successfully synthesized by facile coprecipitation method. The XRD analysis shows the samples crystallized by cubic structure. The refined structure factors from profile refinement were used to analyze charge density distributions in the samples, bond length and mid bond electron densities through maximum entropy method. The charge densities maps revealed that the $\mathrm{Ni}-\mathrm{O}$ bonds exhibit covalent in nature. The SEM analyses indicate that the samples are uniform surface morphology.

\section{ACKNOWLEDGEMENT}

The author S. Sasikumar is gratefully thank to Kalasalingam Academy of Research and Education for their stable encouragement, recognition and financial support as the Post Doctoral Research Fellowship.

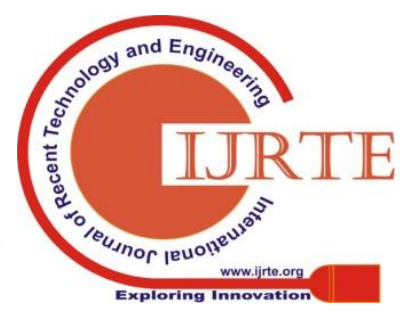




\section{REFERENCES}

1. M. Alagiri, S. Ponnusamy, C. Muthamizh chelvan, Journal of Master Electron, Vol. 23, pp. 728-732 2012.

2. Subhash Thota, Jitendra Kumar, Journal of physics and chemistry of solids, vol. 68, pp.1951-1964, 2007.

3. G. Anandha Babu, G. Ravi, M. Navaneethan, M. Arivanandhan, Y. Hayakawa, Journal of Mater sci: Master Electron, vol. 25, pp. 52315240, 2014.

4. A.K. Mishra, S. Bandyopadhyay, D. Das, Journal of Materials Research Bulletin vol. 47, 2288-2293, 2012.

5. L. Miaomiao, J Chang, S. Jing, G. Lian, Journal of Elecrochimica Acta, vol. 107, pp. 9-15, 2013.

6. R. Murugan, G. Ravi, G. Vijayaprasath, S. Rajendran, M. Thaiyan, M. Nallappan, M. Gopalan and Y. Hayakawa, "Ni-CeO $\mathrm{C}_{2}$ spherical nanostructures for magnetic and electrochemical supercapacitor applications" Physical Chemistry Chemical Physics, vol. 19(6), pp.4396-4404, 2017.

7. J. Bahadur, D. Sen, S. Mazumder and S. Ramanathan, "Effect of heat treatment on pore structure in nano-crystalline NiO: a small angle neutron scattering study". J Solid State Chem, vol. 181(5), pp. 1227 $1235,(2008)$

8. I. Hotovy, J. Huran, L. Spiess, S. Hascik, V. Rehacek, "Preparation of nickel oxide thin films for gas sensors applications", Sensors Actuators B Chem, vol. 57(1), pp.147-152, (1999).

9. T. Nathan, A. Aziz, A.F. Noor, S.R. Prabaharan, Nanostructured NiO for electrochemical capacitors: synthesis and electrochemical properties. J Solid State Electrochem, vol. 12(7-8), pp. 1003-1009, 2008.

10. C.G. Granqvist, (ed), Handbook of inorganic electrochromic materials. Elsevier, New York, 1995.

11. Q.A. Pankhurst, J. Connolly, S.K. Jones, J.J. Dobson, “Applications of magnetic nanoparticles in biomedicine". J. Phys. D. Appl. Phys. vol. 36(13), pp. R167, 2003.

12. C. Sun, J.S. Lee, M. Zhang, "Magnetic nanoparticles in MR imaging and drug delivery", Adv. Drug. Deliv. Rev, vol. 60(11), pp. 12521265, 2008.

13. M. Mohammadijoo, Z. Naderi Khorshidi, S.K Sadrnezhaad and V. Mazinani, Journal of Nanoscience and Nanotechnology, vol. 4(1),pp. 6-9, 2014.

14. M.A. Kiani, M. Abbasnia Tehrani, H. Sayahi, Journal of Analyticachimica Acta, vol. 839, pp. 26-33, 2014.

15. L. Shaohui, J. Jianfeng, W. Jiao, L. Shijiang, W. Xinchang, S. Honghang, H. Xing, Journal of Magnetism and Magnetic Materials vol. 324, pp. 2070-2074, 2012.

16. Z.K. Sohaib, Y. Yudie, A. Amin, S. Marc, C. Philip, L. Lin, L. Zhu, S. Martin, K. G. Watkins, Journal of Nanoparticle Research, vol. 11(14), pp. 21-1427, 2009.

17. B. Reeti, R. Soumyendu, K. Nikhil, D.S. Misra, Journal of Carbon, vol. 56, pp. 56-63, 2013.

18. H.M. Rietveld, J. Appl. Crystallogr. Vol. 2(2), pp. 65, 1969

19. D.M. Collins, Electron density images from imperfect data by iterative entropy maximization, Nature, vol. 298, pp. 49-51, 1982.

20. V. Petricek, M. Dusek, Palatinus, Jana, the crystallographic computing system (Institute of Physics), Praha, Czech Republic (2006).

21. M.A. Rahman, R. Radhakrishnan, R. Gopalakrishnan, "Structural, optical, magnetic and antibacterial properties of $\mathrm{Nd}$ doped $\mathrm{NiO}$ nanoparticles prepared by co-precipitation method", Journal of Alloys and Compounds, vol. 742, pp. 421-429, 2018.

22. S. Saravanakumar, R. Saravanan, S. Sasikumar, Chem. Pap, vol. 68 (6), pp.788-707, 2014

23. K. Momma, F. Izumi, VESTA 3 for three-dimensional visualization of crystal, volumetric and morphology data, J. Appl. Crystallogr. Vol. 44, pp.1272-1276, 2011.

24. K. Momma, F. Izumi, Comm. Crystallogr. Comput. IUCr Newslett. Vol. 7, pp. 106, 2006.

\section{AUTHORS PROFILE}

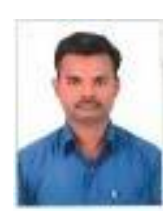

S. Sasikumar received his Ph.D degree in 2018 at Madurai Kamaraj University, India. He has expertise in the area of piezoelectric applications. He has published 19 peer reviewed research articles in international Journal with 56 citations.

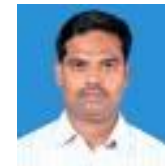

S. Saravanakumar received his Ph.D. degree in 2015 at Madurai Kamaraj University, India. He is expertise in the areas of spintronics materials and the structural and magnetic properties of semiconducting material. He has published 26 peer reviewed research articles in international Journals with over 107 citations.

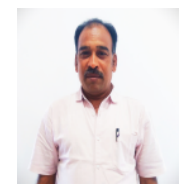

Dr. S. Asath Bahadur is a Senior Professor in the Department of Physics, School of Advanced Sciences a Kalasalingam Academy of Research and Education, India. He has obtained Ph.D. in the area of X-ray crystallography from Madurai Kamaraj University in 1994. He has expertise in the areas of Crystallography and Material science. He has published more than eighty five peer-review research articles in journals of international repute besides seventy more as proceedings.

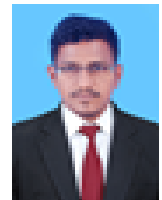

D. Sivaganesh is a Ph.D student at Kalasalingam University, India. His research interest is in structural and photoluminescence properties of phosphor materials. 